\title{
The targeting of US28 is dependent on GASP-I
}

\author{
Elisabeth Moser ${ }^{1}$, Pia Tschische ${ }^{1}$, Wolfgang Platzer ${ }^{1}$, Veronika Pommer ${ }^{1}$, \\ Dawn Thompson ${ }^{2}$, Helmut Schaider ${ }^{3}$, Lene Martini ${ }^{2}$, Jennifer Whistler ${ }^{2}$ and \\ Maria Waldhoer*1
}

\author{
Address: ${ }^{1}$ Institute of Experimental and Clinical Pharmacology, Medical University of Graz, 8010 Graz, Austria, ${ }^{2}$ Ernest Gallo Clinic and Research \\ Center, University of California San Francisco, CA 94608, USA and ${ }^{3}$ Department of Dermatology, Medical University of Graz, 8036 Graz, Austria \\ Email: Maria Waldhoer* - maria.waldhoer@medunigraz.at \\ * Corresponding author
}

from I5th Scientific Symposium of the Austrian Pharmacological Society (APHAR) Joint meeting with the Hungarian Society of Experimental and Clinical Pharmacology (MFT) and the Slovenian Pharmacological Society (SDF)

Graz, Austria. 19-21 November 2009

Published: 12 November 2009

BMC Pharmacology 2009, 9(Suppl 2):AI doi:I0.| |86/I47|-22 I0-9-S2-A I

This abstract is available from: http://www.biomedcentral.com/I47I-22 I0/9/S2/A I

(C) 2009 Moser et al; licensee BioMed Central Ltd.

\section{Background}

The human cytomegalovirus (HCMV) encodes the seven transmembrane $(7 \mathrm{TM}) / \mathrm{G}$ protein-coupled receptor (GPCR) US28. US28 is able to endocytose and signal in a constitutive - i.e. ligand-independent - manner and is located predominantly in the membranes of intracellular organelles, especially late endosomes/lysosomes and multivesicular bodies (MVBs). It was suggested that the virions of HCMV may be budding into the membranes of these MVBs, where the viral receptors are then incorporated into the viral membranes during the final stages of virus assembly.

\section{Methods}

Protein-protein interaction between US28 and GASP-1 (G protein-coupled receptor-associated sorting protein-1) was investigated by GST-fusion protein-binding assay, MBP protein competition binding assay and co-immunoprecipitation. In HEK293 cells endogenously expressing GASP-1 the interaction between US28 and GASP-1 was disrupted by i) overexpression of dominant negative cGASP-1 or by ii) shRNA knock-down of endogenous GASP-1. The role of GASP-1 in the post-endocytic trafficking of US28 was analyzed by means of immunocytochemistry and biotin protection degradation assay.

\section{Results}

Here we show that GASP-1, which sorts many GPCRs to the lysosomes, also plays an important role in the postendocytic targeting of US28. We find that disruption of the GASP-1/US28 interaction by either i) overexpression of dominant negative cGASP-1 or by ii) shRNA knockdown of endogenous GASP-1 is sufficient to alter the lysosomal targeting of US28 and also its post-endocytic degradation.

\section{Conclusion}

Our data suggest that the interaction of US28 and GASP-1 has important implications for the post-endocytic fate of US28. 